\title{
Assessing moisture in porous traditional building materials
}

\author{
S. Rhee-Duverne ${ }^{a^{*}}$, I. McCaig ${ }^{\mathrm{b}}$, S. Orr ${ }^{\mathrm{c}}$, H. Zhang ${ }^{\mathrm{d}}$, H.A. Viles ${ }^{\mathrm{d}}$ \\ ${ }^{a}$ Historic England, UK; ${ }^{b}$ formerly of Historic England, UK; ${ }^{c}$ Institute for Sustainable Heritage, UCL, UK ${ }^{d}$ School of Geography and the Environment, University \\ of Oxford, UK
}

\begin{abstract}
Historic England is often asked for advice on damp problems in historic and traditional buildings. Whilst many different methods are commonly used to assess damp problems in walls, all have some drawbacks. There is lack of agreement over how they should be used and little information about how they compare one with another. This project developed a common methodology in the laboratory to compare the performance of a range of invasive and non-invasive moisture measurement methods used to assess moisture in porous masonry. The findings suggested that most of the measurement techniques can provide good semi-quantitative estimates of moisture levels in porous traditional building materials. Peer-review under the responsibility of the organizing committee of the ICMB21.

Keywords: Moisture measurement; invasive and non-invasive techniques; traditional porous building materials; gravimetric testing
\end{abstract}

\section{Introduction}

Water is, arguably, the greatest cause of damage to historic buildings. Historic England is increasingly asked to provide advice on damp problems, often as a consequence of climate change. The growing frequency of flooding events, the unintended consequences of energy efficiency retrofit, and insufficient repair and maintenance of buildings mean that reliable in-situ moisture assessments are becoming more critical. While there is good theoretical understanding of moisture regimes within porous building materials [1-3], and many modelling based studies, there are a lack of accurate in-situ measurements. Where data exist, there is a lack of confidence in their accuracy and comparability, because there are many techniques based on different physical phenomena and techniques.

\subsection{Aims and objectives}

There are many ways to measure moisture in porous building materials. None is completely effective and all have their limitations [4]. The overall aim of the research was to provide an inter-comparison of the performance of different non-invasive and invasive methods of measuring moisture within typical porous materials likely to be found in historic buildings. The objectives were:

- $\quad$ to assess the performance of different measurement methods during wetting and drying tests;

- to investigate the effect of evaporation conditions on sealed and unsealed samples, with the sealed samples simulating conditions found in real buildings;

- to test the influence of different porous building materials, the effect of salinity and metal components;

- to assess the penetration depth of some of the non-invasive methods.

The data collected allow Historic England to provide better information on the use and limitations of different moisture measurement methods for assessing damp historic masonry. The outputs of the study will be used to inform an Historic England Technical Advice Note for building professionals on how to carry out moisture assessments in-situ.

\section{Methodology}

The methodology developed was laboratory based, similar to that proposed by Eklund et al. [5] and used test blocks of common historic building materials (limestone, sandstone, brick and lime mortar), under controlled conditions of wetting and drying. A wide range of non-invasive and invasive moisture measurement devices was tested, including commercially available hand-held resistance and capacitance devices and microwave methods, as well as dowels, relative humidity sensors and TDR (Time Domain Reflectometry) probes. The values of each method tested was compared with absolute moisture contents (expressed as \% dry weight), obtained by gravimetry. The gravimetric test is the most accurate method available as it determines the absolute moisture content by comparing the wet weight of a sample to its oven-to-dry weight. It is often used as a benchmark for comparing all other methods or for calibration [6].

Experiments were also carried out to evaluate the influence of drying conditions, sample size and depth, effect of salinity and the presence of metal components. Also, the performance of novel ceramic dowels was compared with conventional wooden dowels. Lastly, limited fieldwork was carried out to explore the usefulness of the invasive and non-invasive microwave moisture measurements in comparison with wooden dowel surveys.

\section{Results}

*Corresponding author. +44 (0) 7810852 562, soki.rhee-duverne@historicengland.org.uk

(C) The Author(s). This is an open access article distributed under the terms of the Creative Commons Attribution License (CC BY) 4.0 https:// creativecommons.org/licenses/by/4.0/, which permits unrestricted use, distribution and reproduction in any medium, provided the original author and source are credited. DOI: 10.14293/ICMB210054 
The results indicated that under controlled laboratory conditions, most of the tested techniques can give reasonably good, semiquantitative estimates of moisture levels in the types of porous materials used in historic buildings. A few of the non-invasive hand-held devices were found to be effective to assess drying conditions for all materials, particularly the dieletric pinless moisture meter (CEM, Shenzhen, China and 4-pin resistance meter (Resipod; Proceq, Schwerzenbach, Switzerland) meters. Both provided reliable readings over a large range of conditions, from near-dry to near saturated. The Resipod meter also performed well under the experimental wetting conditions. Several non-invasive techniques, notably the TDR, the wooden dowel and the Protimeter deep wall probe have also been effective, as long as care is taken to achieve good fit when installing the probes.

Material characteristics have also found to influence the results, Figure 1, however, it is not advisable to directly compare meter readings from different building materials.

(1a)

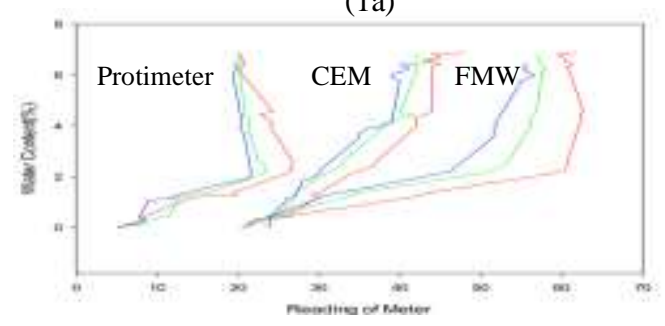

(1b)

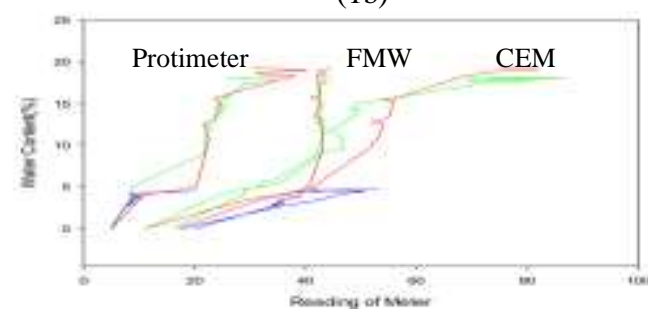

Figure 1a. Drying tests with measurements from Protimeter (r/m mode), Wood Moisture Meter, FMW (PCE Instruments; Southampton, UK) \& CEM devices plotted against moisture contents for three large Portland limestone samples.

Figure 1b. Drying tests with measurements from Protimeter ( $\mathrm{r} / \mathrm{m}$ mode), FMW \& CEM measurements plotted against moisture content for three brick samples.

With exception of the microwave meter Moist350B, salinity influenced the results by changing the effective range of the different devices. The Moist350B (non-invasive sensors) has the advantage over other devices to scan large areas rapidly to locate areas of damp. In all non-invasive meters metal components near to the surface of the measurement location created uncertainty. Results from drying and wetting experiments were broadly similar; however, the datasets from the wetting experiments were more variable. The drying experiments provided a good simulation of historic masonry after a flood, and the wetting experiments provided an effective simulation of the impact of driving rain on dry walls. In these instances, using a combination of techniques was found to be useful: the microwave moisture meter was sensitive to rapid wetting (that simulated rain spells), whilst the timber dowel was slower to respond suggesting that a combination of techniques would be useful for assessing drying after a flood.

\section{Discussions and Conclusions}

Many factors affect the assessment of moisture in porous traditional building materials. Interpretation is challenging as the techniques are based on a variety of different scientific principles. Many only have arbitrary scales and these values are simply non-absolute indicators of higher or lower moisture contents. Furthermore, the value of the measurements depends on the experience of the user to interpret the results. Practical issues of handling between practitioners also influence the readings: some require good contact, and with others, the amount of pressure applied or the degree to which the probes have penetrated a substrate affect the measurements.

Calibration is another factor as commercial devices are usually calibrated for one type of material. Manufacturers sometimes provide conversion tables or specific calibration values for generic materials, but evaluating their accuracy is difficult because of the non-homogeneity of historic materials, ageing, salts and weathering. Most historic buildings are composite structures, which adds another level of complexity in assessing moisture.

The limited fieldwork demonstrated the need to use a combination of different moisture measurement devices with surveying techniques, and contextualise the readings within the building environment.

The experimental methodology used in this research project provides one way to assess the performance of different methods under a range of conditions, and enable more rigorous comparisons between different datasets.

\section{References}

[1] Hall, C. \& Hoff, W.D. (2002). Water transport in brick, stone and concrete. London, UK: Spon Press.

[2] Hall, C. \& Hoff, W.D. (2007). Rising damp: capillary rise dynamics in walls. Proceedings of the Royal Society A 463, $1871-1884$.

[3] Hall, C., Hamiliton, A.. Hoff, W.D., Viles, H.A. \& Eklund, J.A. (2011). Moisture dynamics in walls: response to micro-environment and climate change. Proceedings of the Royal Society A, 467, 194-211.

[4] Pinchin S. (2008). Techniques for measuring moisture in walls. Reviews in Conservation 9, 33-45.

[5] Eklund, JE., Zhang, H., Viles, HA., \& Curteis, T. (2013). Using handheld moisture meters on limestone: factors affecting performance and guidelines for best practice. International Journal of Architectural Heritage, 7, 207-224.

[6] ASTM. (2003). Standard test methods for use and calibration of hand-held moisture meters, D4444-92. 